\title{
Impact of Digitalization on the Industrial Enterprises Activities
}

\author{
A.A. Chudaeva ${ }^{1, *}, V . V$. Mantulenko $^{1}, P$. Zhelev $^{2}$ and $R$. Vanickova ${ }^{3}$ \\ ${ }^{1}$ Samara State University of Economics, Samara, Russia \\ ${ }^{2}$ University of National and World Economy (UNWE), Sofia, Bulgaria \\ ${ }^{3}$ Institute of Technology and Business, České Budějovice, Czech Republic
}

\begin{abstract}
The relevance of the study is determined by the change of technological structure of the Russian economy: digital technologies are becoming an integral part of the fulfilling life of both individual and legal entities. The use of digital technologies in the activities of manufacturing enterprises allows them to become more competitive. However, the change in almost all processes of an enterprise because of digitalization simplifies some of them and reduces their cost but complicates others and makes them more expensive. In addition, the digitalization leads to the emergence of new processes at enterprises that often means the emergence of new risks and additional costs.

The purpose of this research is to study the impact of the digitalization on activities of industrial enterprises. Objectives of the study are: to study the concept of digitalization, areas of activity of industrial enterprises as well as consequences of the introduction of digital technologies into each of the activity area of industrial enterprises and the impact of digitalization on the results of a production enterprise.
\end{abstract}

Keywords: digitalization, digital economy, digital technologies, manufacturing enterprises, information environment.

\section{Introduction}

The digitalization affected the production enterprises of the Russian Federation less than the service and banking sectors, but their further development in the conditions of fierce competition for consumers and limited resources is impossible without the use of digital technologies [1].

Digital technology implemented in the activities of production companies can qualitatively change the production process. Enterprises of the real sector of the economy have a much longer period of turnover of invested funds because of the production stage. And in comparison with enterprises and organizations engaged only in sales or services, the scope of digital technologies in the real sector of the economy is much wider. Due to digital technologies, the virtual part is combined with the real one which leads to the possibility of creating a "world based on real events". In this world, it is possible to conduct modeling, testing of new products, their improvement, etc. in the virtual (not real) environment that reduces costs of development, implementation and sale of products manufactured by the enterprise.

In the digital economy (economy based on new methods of generating, processing, storing and transferring data, as well as digital computer technologies), the key factor of production is data in the digital form that become a part of the added value, a new asset that ensures the successful functioning of business and competitive development of production. However, results of the introduction of digital technologies are not always direct and easily measurable.

Nowadays, this issue is actively considered by Russian and foreign researchers: Ananyin et al. [2], Bauer et al. [3], Garifova [4], Haag et al. [5], Kozyrev [6], Lopez-Nicolas \& Soto-Acosta [7], Rudenko [8] and others.

\section{Problem Statement}

The introduction of digital technologies in production can be viewed from two sides. On the one hand, it is the production of new products that did not exist before (including the production of digital technologies themselves). Such types of production are initially created on the technological basis corresponding to the modern development level of science and technology (in fact - to a new technological order which doesn't have any common and by everybody accepted name at present). On the other hand, it is the production of goods familiar to the market for a long time but on a new technological basis with the introduction of new methods in the existing production, improvement/modernization of existing production processes. The introduction of digital technologies leads to a fundamentally new business structure and organization of the business processes that can be observed in different areas.

Goods produced in the context of the digitalization acquire many "digital attributes" which couldn't hardly ever exist in the "non-digital" era. Thus, the very use of these products is often impossible without digital technologies. The creation of products in their material form is preceded by its digital representation. The information about the product is accompanied by various data in electronic form. A lot of services related to products can also be digital.

Obviously, the digital transformation affects not only the production area of enterprises but also the whole system of business organization and functioning. All processes related to the production of the enterprise are changing: some of them are algorithmized and digitalized while reducing transaction costs of the company. Therefore, the results of this 
study are significant for both industrial enterprises and society. The study is aimed at the practical use of planned results in the activities of enterprises in the real sector of the Russian economy.

\section{Research Questions}

Results that can be obtained due to the introduction of digital technologies in the activities of industrial enterprises should be considered from the perspective of transformation in the value chain: according to the areas of enterprise activities: product design, production, logistics, marketing and sales, service, safety, personnel. Obviously, we should use quantitative rather than qualitative indicators while determining the impact of digitalization on the activities of manufacturing enterprises. In a market economy, the purpose of a production enterprise is to obtain a net profit. Therefore, in the study, issues of interest are results that can be estimated in monetary terms.

\section{Purpose of the Study}

The purpose of this research is to study the impact of the digitalization on activities of industrial enterprises. Directions of results increasing due to the introduction of digital technologies in business processes are potentially huge: labor productivity increases, the number of products produced per unit of time rises, as a result, income increases too. However, the introduction of digital technologies requires costs. And industries that implement information technology are capital-intensive. Therefore, there may not be a direct relation between the increasing level of income of the enterprise from the sale of products and the use of processes and equipment integrated with digital technologies. Costs for acquiring a new generation of technical systems may be so high that they will not pay off in the foreseeable future. Here, we need calculations and justification taking into account all the factors that will be influenced by the digitalization. Thus, the introduction of digital technologies in the activities of economic entities is often determined by their ability to radically reduce the level of transaction costs and change their structure.

\section{Research Methods}

The authors used such research methods as analysis, synthesis, description and comparison. Their application is determined by the theoretical nature of the study which included the following stages: formulation of the problem, analysis of information on this topic, comparison and description of different scientific views on the studied issues, synthesis of different approaches to the problem.

\section{Findings}

\subsection{Product design}

Digitalization changes the product design processes of a manufacturing company as follows:

- when designing products, its use with "digital support" is taken into account, i.e. with the use of software that allows the product use,

- product design becomes impossible without knowledge of software and programming skills which in turn leads to changes in the structure of employees,

- innovative products, unlike traditional ones, can be transformed by changing the software that is part of these products,

- availability of software in hardware (labor means) allows to make it(them) more flexible (changes in the algorithm of actions in the software or software replacement lead to the transformation of products),

- in the context of digitalization, the development of powerful digital interfaces becomes a necessary design stage,

- the opportunity to simulate the behavior of products in different conditions, consider different scenarios allows us to reduce the subsequent costs associated with service and post-service,

- the possibility of total control over the production process in real time can lead to improved product quality,

- the opportunity to test products in conditions that are as close as possible to the real operating environment,

- the possibility of using software for the designed products that allows to perform diagnostic work and reduce the negative consequences of the failure of the technical system or its individual parts;

- while designing we should take into account the new format of product sales: at present, many companies are working on the scheme "product as a service", i.e. they sell not only products, but also services (often in the scientific literature this business format is called "service business model"), therefore, in the process of product development it is necessary to take into account that costs associated with product maintenance will lie on the manufacturer, not on the consumer,

- if the equipment used in the production is a direct part of the whole system of the enterprise, there is a possibility of its optimization in a larger volume than it was possible in the "pre-digital era". 


\subsection{Production}

Production will change with the introduction of digitalization as follows:

- in the context of digitalization, some types of products (including means of labor) become one with cloud technologies, without these tools the physical part of the product cannot function, that leads to the need for maintaining and improving products during their whole life cycle and, consequently, production becomes a constant process,

- the use of digital technologies allows to carry out a part of the production processes on the territory of the consumer, for example, the installation and configuration of software (in fact, the last stage of the product creation is its assembling, installation),

- the possibility of combining the equipment of the production enterprise on the basis of digital technologies into a network leads to the automation of production processes and their optimization which, in turn, allows to prevent the occurrence of emergency situations at the enterprise and inform employees about them,

- the opportunity to extend the functionality of technical systems through the software can lead to the abolition of some physical components,

- industrial production under the conditions of digitalization has the opportunity to create standardized platforms that can be customized to the requirements of a particular consumer that leads to a reduction in stocks of goods and materials and the emergence of a scale effect (economy of scale).

\subsection{Logistics}

The logistics of the production enterprise is changing due to the fact that digital technologies allow real-time tracking of product movements, its characteristics and the state of the environment. In addition, the emergence of automatic drones that deliver orders to customers directly to their homes can dramatically transform the logistics processes.

\subsection{Marketing and sales}

The company's activities in the field of marketing and sales of products of an industrial enterprise are transformed as follows:

- digital technologies (in particular, BigData technologies) allow to accumulate information about consumers from social networks and other sources in which consumers leave a "digital footprint" allowing to evaluate their preferences, characteristics, etc., that creates new technologies for market research and sales,

- digital technologies make it possible to change the format of relations with the market and a particular consumer: in the world where, due to the digitalization and the ubiquitous spread of the Internet, everything has become transparent and revives the institution of reputation, the manufacturer benefits from a long and mutually advantageous relationship with the consumer,

- digital technologies allow to accumulate information about the behavior of the technical system during its operation, this information can be taken into account by the next design process and enables to carry out the segmentation of the market and consumers more carefully,

- the opportunity to improve characteristics of products used during the entire period of their life cycle leads to a change in communication between the consumer and the manufacturer and the transformation of the essence of sales: it is now implemented as a service and, as a rule, it is not a short-term service,

- individual units of production can be combined into a system which will lead to a synergistic effect.

\subsection{Service maintenance}

Service is changing in digitalization conditions as follows:

- the solution of problems arising in the operation process gives way to processes allowing to prevent the occurrence of these problems, that leads to the transformation of the very essence of service maintenance: the focus shifts towards preventive and proactive measures, as well as remote inspection,

- manufacturers of technical systems (who maintain long-term service communication with the consumers of their products with the help of the software used in these systems) have the opportunity to increase the income of their enterprise through the provision of maintenance services,

- the opportunity to diagnose a problem in real time leads to a shorter period of time during which this problem will be solved,

- digital technologies provide an opportunity to remotely monitor the status of products and their repair in some cases (when the problem can be solved by working with their software),

- with the help of special software, we can remotely monitor the product condition and if the software allows to work remotely with it and through it influence the condition of the product, then repairs can be made "at distance" (remotely) too,

- digital technology allows to collect information about the behavior of products, analyze it, and, as a result, prevent the occurrence of failures, 
- arrays of information collected by the new generation of technical systems provide service departments of the enterprise with the opportunity to independently communicate with consumers, which allows to solve not only service but also design problems in the process of communication.

\subsection{Security}

Digitalization changes the security requirements of a manufacturing enterprise as follows:

- issues of industrial espionage have reached an absolutely new level because of the widespread application of digital technology - manufacturing enterprises spend huge amounts of money on the protection of enterprise systems, its databases, computers and networks,

- consumers of products manufactured by an enterprise require the high level of security in all its types - information security, economic security, fire safety, environmental safety, etc.

\subsection{Staff}

Digitalization has an impact on requirements to the personnel of a manufacturing enterprise, and on interaction processes of personnel within the enterprise:

- manufacturing enterprises have needs for new competencies, knowledge, skills and abilities of employees, a new style of work and culture in the conditions of the digitalization,

- needs of the manufacturing enterprises for personnel change: the production departments need more programmers who are capable to solve problems with the software, sellers of the production should be managers who can sell not only products themselves but also service (from sellers of goods - to sellers of service), service specialists should have not only repair skills but also be experts in the field of technical support of production

- in the context of digitalization, enterprises need specialists who can work with data and have skills to build an automatic analysis of these data, as well as specialists in the system integration, software development and user interface development,

- digitalization will lead to the transformation of the organizational structure of manufacturing enterprises, relationship between specialists, the emergence of new forms of labor stimulation and building new relationships between employees and their employers.

\subsection{Business processes}

Business processes are digitized, i.e. the processes of operating a digital product become digital themselves. This is very noticeable in the document flow of an enterprise: many documents have become digital. Participants of business processes of the enterprise have the opportunity to work with digital documents, using special applications that require coordination of users, special applications of software and data. Purchase and application of different software is costly for the enterprise, it requires both capital and current costs.

\section{Conclusion}

Digitalization leads to the emergence of such an opportunity as management of the organization in "real time" (Real Time Enterprise, RTE), which allows to receive information without delay, in the mode close to "real time". The combination of fast accumulation of knowledge, the dominant culture focused on changes and flexible forms of organization reduce the time (and, therefore, reduce the costs of the enterprise) and improve the quality of decisionmaking process at all levels of business management.

Rapid decision-making and a higher level of quality of decisions allow to implement these decisions faster, that can increase the competitiveness of the company in the market. However, it also generates a high degree of variability of processes within the enterprise, which, in turn, can be costly.

It is widely believed that the introduction of digital technologies will release a large number of employees, because they will be replaced by robots. However, such fears are not entirely justified. Indeed, staff requirements will change, and many processes will be automated or even eliminated. But we must not forget that only those functions that are easily algorithmized because of their homogeneity and repeatability from process to process are amenable to automation. However, there are functions that currently cannot be automated. Therefore, the staff of the enterprise will have other qualitative characteristics that, finally, will be reflected in quantitative indicators - labor costs of staff and outsourced personnel.

In addition, the stages of implementation and debugging of digital technology can be very long in time, which not only leads to a reduction in personnel costs, but also increase them - the specific result depends on the type of production, the nature of functions performed by the personnel and the possibility of replacing employees by means of labor combined with digital technology. 


\section{References}

1 Government of the Russian Federation (2017). The program "Digital Economy of the Russian Federation", approved by the Order of the Government of the Russian Federation of July 28, 2017 No. 1632-p. URL: http://static.government.ru/media/files/9gFM4FHj4PsB79I5v7yLVuPgu4bvR7M0.pdf. Accessed: 4.02.2019.

2 V.I. Ananyin, K.V. Zimin, M.I. Lugachev, R.D. Gimranov, \& K.G. Skripkin, Digital enterprise: Transformation into a new reality. Business Informatics, 2(44), 45-54. URL: https://elibrary.ru/item.asp?id=35233562 (2018).

3 W. Bauer, M. Hämmerle, S. Schlund, \& C. Vocke, Transforming to a hyper-connected society and economy towards an "Industry 4.0". Procedia Manufacturing, 3, 417-424. DOI: 10.1016/j.promfg.2015.07.200 (2015).

4 L. Garifova, The economy of the digital epoch in Russia: Development tendencies and place in business. Procedia Economics and Finance, 15, 1159-1164. DOI: 10.1016/S2212-5671(14)00572-3 (2014).

5 S. Haag, C. Bauerdick, A. Campitelli, R. Anderl, E. Abele, \& L. Schebek A framework for self-evaluation and increase of resource-efficient production through digitalization. Paper presented at the Procedia CIRP, 72, 850-855. DOI: 10.1016/j.procir.2018.03.304 (2018).

6 A.N. Kozyrev, The digital economy and the digitization in the historical retrospective. Electronic Scientific Journal "Digital economy". URL: http://digital-economy.ru/stati/tsifrovaya-ekonomika-i-tsifrovizatsiya-v-istoricheskojretrospektive (2017).

7 C. Lopez-Nicolas, \& P. Soto-Acosta, Analyzing ICT adoption and use effects on knowledge creation: An empirical investigation in SMEs. International Journal of Information Management, 30(6), 521-528. DOI:10.1016/j.ijinfomgt.2010.03.004 (2010).

8 G. Rudenko, Digital technologies: New business opportunities. Effective Crisis Management, 1(82), 42-47. URL: https://elibrary.ru/item.asp?id=21491237 (2014). 